\title{
La guerra civil desde la postguerra. Apuntes sobre la persecución religiosa en Córdoba
}

\author{
José García-Cuevas Ventura
}

En este somero análisis, centrado preferentemente en las consecuencias de la persecución religiosa en la guerra civil de 1936, nos hemos servido, como fuentes primarias, de las noticias y apreciaciones contenidas en el diario Córdoba, así como en el Boletín Oficial Eclesiástico de la diócesis, durante los tramos iniciales de la postguerra '. Advirtamos que, en nuestra aproximación, nos conduciremos desde los temas generales a los particulares.

En 1943, la conmemoración del Alzamiento se materializó en las páginas del diario de FET y de las JONS mediante una amplia referencia a diversos aspectos de la contienda. Bajo el título: «La Iglesia y el Nuevo Estado", se ofrecian interesantes valoraciones sobre el papel de la institución eclesiástica durante el período bélico, y su situación ulterior, ponderando en todo momento la labor ejercida por el Estado franquista. Se reparó, por ejemplo, en el efecto que la polémica Carta Colectiva del 1.. de julio de 1937 tuvo sobre la opinión católica mundial: "La Iglesia española habia librado y ganado la más grande batalla por España. El mundo católico se había puesto al fin a nuestro lado" ${ }^{2}$. No se dudó al afirmar, recurriendo a la manida teoría de la conspiración, que la propaganda masónica era responsable de las contadas voces disonantes. Para el cronista, la postura de la Iglesia docente había sido clara desde el primer

\footnotetext{
1 En julio de 1941, el periódico falangista Azul se transtormó en Córdoba, incluido en la cadena de prensa del Movimiento. Vid. CHECA Godoy, A., Historia de la prensa andaluza, Sevilla, 1991, págs. 368, 377-78. Concretamente, el número cero está fechado el domingo, día 20, de aquel mes y año.

Córdoba, 18 de julio de 1943, pág. 4. Entre una nutrida bibliografía, sobresale la sólida exposición de Cuenca ToRiBio, J. M., Relaciones Iglesia-Estado en la España Contemporánea, $2 .{ }^{\text {a }}$ ed., Madrid, 1989, en especial, su capitulo III, obligado referente de estas páginas.
} 
momento, pues "con maravillosa intuición (...) comprendió el santo carácter de la Cruzada y bendijo la empresa que empezaba" ${ }^{3}$. Recordó, en especial, la transcendencia de algunos documentos magisteriales, entre los que citaba la pastoral Las dos ciudades, de Pla y Deniel, obispo de Salamanca; la Instrucción de Mateo Múgica y Marcelino Olaechea, obispos de Vitoria y Pamplona, o El caso de España y la Carta a Aguirre, del cardenal primado, Isidro Gomá. Para el autor de aquellas líneas, alcanzada la victoria y bajo la égida del Caudillo, el catolicismo ensanchaba el radio de su acción benéfica, cauterizaba las heridas abiertas tras ocho años de persecución (sic), se reconstituía, aumentaban las vocaciones religiosas, las sedes episcopales eran cubiertas, merced al convenio suscrito entre el Estado español y la Santa Sede (7-VI-1941), ejercía su autoridad en la enseñanza y en la cultura, las costumbres se moralizaban con las disposiciones gubernamentales e inspiraba, en fin, toda la obra del régimen.

El estallido de la paz dio paso a una auténtica floración de las prácticas piadosas. De entre ellas, una parecía reunir todos los elementos que le permitirian descollar sobre las restantes: la devoción al Corazón de Jesús. Habiendo conocido entre los fieles un espectacular desarrollo tras la orientación cristocéntrica decimonónica, muy pronto, a su carácter sentimental y reparador, se adhirieron ribetes teocráticos, siendo para no pocos la insignia de los resistentes al espíritu de la Modernidad. En 1919, en la cima del Cerro de los Ángeles, centro geográfico peninsular, se había inaugurado el monumento al Sagrado Corazón, que, como es sabido, sería dinamitado en la vorágine de la guerra. Lógicamente, una vez finalizada, convertido para los vencedores en símbolo de la barbarie "roja", cundió el deseo de erigir uno nuevo.

En efecto, don Adolfo Pérez Muñoz, ocupante a la sazón de la silla de Osio, haciéndose eco de la misiva del obispo de Madrid-Alcalá, monseñor Eijo Garay, nombraba en 1942 al canónigo José Salinas Anchelerga, delegado diocesano de la Obra Nacional encargada de las campañas de propaganda y suscripción. El ejemplar del diario Córdoba de 2 de julio de 1943 daba cuenta del anteproyecto de Pedro Muguruza. El día 16, intercalado entre las restantes informaciones, encontramos el apremiante aviso: "Constantemente debes recordar que de tu mayor o menor aportación depende el que el cerro de los Ángeles se alce en el centro de nuestro solar como poderoso bastión de nuestra fe y de nuestro patrio- 
tismo" ${ }^{4}$. Sin duda, como incentivo para la empresa, se anunciaría el donativo de cincuenta mil pesetas efectuado por el propio Jefe del Estado para sufragar los trabajos.

En el referido número del 2 de julio también se narraba la aprobación, por la "Asamblea Diocesana del Corazón de Jesús» (Sevilla), de una solicitud para que la solemnidad se declarase fiesta de precepto, con el mismo rango litúrgico que el Corpus. Conscientes, empero, de que su extensión a todo el orbe encontraría algunos inconvenientes, se proponía que el privilegio quedase reservado a la nación hispana, "ya que en España quiere reinar el Corazón de Jesús con mayor veneración que en ninguna parte», según la revelación a Bernardo de Hoyos en 1733, conocida como la "Gran Promesa". En dicha Asamblea, José María Pemán, célebre escritor y propagandista, dijo:

«... se fusiló al Sagrado Corazón de Jesús durante la época del dominio rojo, pero el polvillo de aquella piedra ha prendido en el cerro de San Juan de Aznalfarache, donde al amparo del grandioso monumento alli levantado, los corazones se inundaron de esperanza." 5

En el reportaje ofrecido con motivo de la efeméride de la sublevación militar, en 1943, tuvo asimismo cabida la referencia a la antigua capital del Califato. Con el titular: «Nuestra ciudad fue la primera que se levantó en guerra», y habiendo señalado que, gracias a su posición geográfica y a su actiłud, "salvó a Andalucía", se evocaron con apasionamiento los ataques del enemigo:

"Nuestra católica ciudad vio (...) que el odio demoníaco que movía a los rojos trató de reducir a escombros nuestras iglesias bombardeándolas cobarde y deliberadamente, y el cristiano fervor vio la rabia de los rojos contra San Rafael y los Dolores, contra Santa Marina y la Catedral. En las primeras marcaron huellas indelebles. En nuestra incomparable Mezquita, quedaron los proyectiles sin estallar en los tejados.

Nuestra fe y nuestro patriotismo nos dieron alientos para combatir contra la barbarie y gracias a Dios y a nuestro bendito Custodio, salió salva Córdoba de la tragedia." ${ }^{6}$

4 Ibid., 16 de julio de 1943, pag. 3. Eran frecuentes las peregrinaciones organizadas a la Basilica del Pilar (Zaragoza), que pasó a denominarse "Templo Nacional y Santuario de la Raza", al Santuario de la Gran Promesa (Valladolid), y al propio Cerro de los Ángeles, lugares de culto que sintonizaban plenamente con la concepción político-religiosa imperante tras el enfrentamiento tratricida, cfr. CUENCA TORIBio, J. M., op. cit., pág. 90.

5 Córdoba, 2 de julio de 1943, pág. 1.

6 Ibid., 18 de julio de 1943, pág. 7. La rotulación del anónimo artículo es coincidente con los planteamientos de los periodistas Duran de Velitla, M. y Garcia Prieto, M., 18 de julio. Episodios 
Por cierto que, en la festividad de San Rafael de aquel mismo año, se recordaba a los lectores, cómo a raíz de su proclamación como patrono de los Caballeros Mutilados de Guerra por la Patria, el propio jefe del Cuerpo, general Milián Astray, visitó la urbe andaluza en 1939, para hacerse cargo de una talla del arcángel, debida a la gubia del gran escultor dieciochesco Duque Cornejo, que desde entonces podía admirarse en el vestíbulo del palacio de la Dirección General, en Madrid.

Por otro lado, en septiembre de 1941 se celebró en el céntrico cine Góngora de la capital cordobesa, la III Asamblea Diocesana de la Juventud de Acción Católica, organización de laicos unitaria, centralizada y muy dependiente de la autoridad jerárquica, en cuyo apostolado se habian depositado grandes esperanzas. El recuerdo de los caídos era palpable; en el escenario, una inscripción rezaba: «7.000 mártires indican la senda". El vicepresidente nacional, Antonio García de Pablos, tras señalar, con tono triunfalista, que España estaba llamada a reconstruir la Cristiandad, designó como virtualidades de la propia contienda, el que miles de indiferentes volviesen a la doctrina eterna, que hubiesen aumentado los bautizos, y que los matrimonios se hicieran con arreglo a los sagrados cánones. Pese a que su estimación pueda adjetivarse de unilateral, también advirtió que el torrente de odio aún existente había que contenerlo con el amor fraterno ${ }^{7}$.

Este mismo deseo parecía alentar las cartas pastorales que, con ocasión de la Cuaresma, dirigiera a su grey el obispo de Córdoba, en los primeros años de la postguerra ${ }^{8}$. Así, por ejemplo, en 1940, expresó su empeño de "ganar la paz", previniendo contra los peligros de que su consecución hubiese sido sólo aparente, cuando en muchas conciencias seguían rugiendo el encono y el desquite ${ }^{9}$. En tales circunstancias, era tarea perentoria, a su parecer, la recristianización de la sociedad. De lo dicho, fácilmente puede inferirse que las alusiones al reciente y dramático

del Glorioso Movimiento Nacional en Córdoba, Córdoba, 1937, pág. 75. Cfr. Moreno Gómez, F., La guerra civil en Córdoba (1936-1939). 2." ed., Madrid, 1986. (Aclaremos que en la cita se alude a los titulares de algunas de las iglesias más representativas de la población, y que su protector ce. leste es, según una secular creencia, San Rafael).

Córdoba, 23 de septiembre de 1941, pág. 4.

\& El perfil humano de un obispo que no escatimó encendidos elogios para la Cruzada, puede hallarse en Cuenca Toribio, J. M. Pueblos y gentes de Córobba, Córdoba, 1993, págs. 127-130. El mismo autor nos brinda una penetrante valoración del testimonio religioso cordobés en la época del llamado nacionalcatolicismo, en su Historia de Córdoba. Córdoba, 1993, pág. 203. Cfr. MORENO Gomez, F., Córdoba en la postguerra. (La represión y la guerrilla, 1939-1950). Córdoba, 1987, págs. $31-40$.

9. Boletin Oficial Eclesiástico del Obispado de Córdoba (BOEOC), 2 (1940), págs, 17-56. 
quiebro en la convivencia pacífica entre los españoles fuesen constantes. Especial interés reviste la siguiente valoración, que, en buena medida, recoge el fundamento doctrinal del bando nacionalista, su "legitimidad histórica", acorde, por to demás, con el que era unánime sentir de la lglesia institucional hispana:

"Fue aquella indudablemente una guerra de salvación; estaban en peligro de hundirse y desaparecer para siempre las esencias intimas de nuestro pueblo; $y$, por consiguiente, amenazaba con perderse también para siempre nuestra España como nación independiente, anulándose con su muerte todo su gloriosísimo pasado histórico, el contenido total de su espléndida civilización. Solamente merced a ese peligro tuvo lugar aquel magnífico despertar colectivo de la conciencia nacional, en un iodo semejante al ocurrido en la guerra de la Independencia, en las guerras religiosas de los siglos $x \mathrm{~V}$ y $\mathrm{XVII}$, y en la epopeya magna de la reconquista; en todas aquellas ocasiones, en fin, en las que como en este momento, estuvo en peligro nuestro ser histórico, religioso y social.

No fue, pues, aquella, como ya os deciamos entonces, una guerra civil, en la que se ventilaran intereses materiales o de indole económico, ni siquiera de carácter político o de expansión territorial; no fue aquello un dirimir, dentro del ambiente de familia, viejas rencillas de dos bandos enemigos; fue un alzarse magnífico de la España inmortal contra la barbarie internacional que, en un momento propicio de la Historia, se abalanzó contra ella pretendiendo despojarla de todo el riquísimo contenido que le habian ido legando las repetidas generaciones de sus hijos ilustres; y en primer lugar del sagrado depósito de fe cristiana, de sus altos designios espirituales, de su católica tradición. Tuvo nuestra guerra honores de Cruzada, y los heroicos paladines que dieron su sangre por España, al defender la santa independencia del suelo patrio, defendian igualmente la supervivencia de las santas tradiciones religiosas de nuestra fe y de nuestro catolicismo. Frente a la bandera de la barbarie rusa: "Sin Dios", España no encontró sino una postura digna y gallarda "Dios". No hicieron con ello nuestros héroes otro cosa que seguir el rumbo que nos trazaron nuestros ascendientes, cuando gloriosamente identificaron la defensa de la gloria de Dios con la defensa de las glorias de la Patria. Siempre fue asi en nuestra España." 10

En 1941, empeñado aún en la recuperación material y, sobre todo, moral de la sociedad española, insistió en la necesidad de construir una auténtica civilización cristiana, cimentada en la justicia y la caridad, que,

16 Lid., págs. 20-21. 1940 fue, ademàs, el año jubilar en que se celebró, según una tradición venerable, el XIX centenario de la venida de la Virgen en carne mortal a Zaragoza. Con motivo de la peregrinación cordobesa al Pilar, Pérez Muñoz escribiría una exhortación pastoral (9-X1-1940), considerando la guerra como un revulsivo necesario para sacudir la atonía moral, aunque también prevenia, conociendo la indolencia de muchos, ante la tentación de contentarse con un simple catolicismo oficial, ibid., 11 (1940), en especial, págs. 221-222. 
obviamente, requería la rectificación de numerosas conductas poco acordes con el espíritu evangélico, aleccionados con el ejemplo de los mártires. Así, pues, tampoco faltó en esta ocasión la referencia a la persecución religiosa. Por cierto que, al recabar recursos para el Seminario, aludiendo a la urgencia de nuevos candidatos al sacerdocio, nos ofrecía una reflexión, que no hemos de desdeñar, pese a su aparente simplismo:

"Cuando se escriba, concienzuda y desapasionadamente, la historia de nuestra revolución; cuando con la serenidad objetiva que solamente se puede tener al apartarse de los sucesos ocurridos, apagados ya los fuegos de las pasiones por las aguas del río de la Historia, se inquiera profundamente en las causas que dieron origen a esta misma revolución, aparecerán a los ojos de los historiadores dos acontecimientos que se han desarrollado, paralelamente, con unas alternativas tan relacionadas entre si, que fácilmente podrá colegirse la influencia que uno de ellos tuvo en el otro.

Como regla general puede establecerse que, donde tuvo más virulencia la revolución, donde fueron sus consecuencias más graves y más hondas, fue precisamente donde menor era el influjo de los sacerdotes en el pueblo, debido principalmente a su escasez, mientras que fue contenida desde sus comienzos, acorralada y vencida en aquellas regiones en las que la abundancia del clero permitia, desde siempre, tener bien atendidas las necesidades espirituales de los pueblos.

Y entre las primeras regiones, aquellas donde más bárbaramente se desencadenó la revolución - triste y muy doloroso es confesarlo- está toda esta nuestra región andaluza, en la que, de muy antiguo, se ha venido luchando con la escasez e insuficiencia del Clero." 11

Al adoctrinar a los cordobeses en 1942, mantuvo algunas de sus pasadas admoniciones, destacando la voluntad del mitrado por extraer, conforme al providencialismo, el componente regenerador del duelo fratricida, por más que tan trágico suceso no hubiese sido promesa de enmienda:

"Nunca hemos dudado del valor expiatorio de nuestra guerra de liberación, en la cual, la sangre de tantos miles de víctimas empapó la tierra, removida por la metralla, de nuestro suelo patrio. El sacrificio de los mejores venía a liquidar el enorme déficit, que con Dios teníamos contraido. A la vez tonificaba el espiritu de los que íbamos quedando. Y la sangre vertida, junto con el poder la oración, nos alcanzó del Dios de las victorias aquellos auxilios superiores, sin los cuales hubieran sido vanos nuestros humanos esfuerzos, para obtener el triunfo salvador de nuestra Patria.

1 Jbid., 3 (1941), págs. 48-49. Prestigiado es el elenco de investigadores que, en efecto, ha reparado en la gran desigualdad existente en la distribución geográfica del clero peninsular, y en las lógicas consecuencias sociales que de ello se derivaban. 
Pero Nos esperábamos fundamentalmente que si la guerra, mirada como pena y castigo de nuestras prevaricaciones individuales y colectivas, tenía el valor vindicativo de reintegrar el orden lesionado de la Justicia divina, también habriamos de reconocer en ella esa virtud medicinal y aleccionadora, que curando nuestras morales enfermedades, nos hiciese entrar por aquellos caminos rectos, que implica el cumplimiento del deber.

Por desgracia, no ha sido así. La lección del futuro, que ella encerraba, no ha sido comprendida, o quizás seriamos más exactos afirmando que no hemos querido comprenderla. Esto decimos a la vista de ciertas lacras morales y espirituales, cuya extensión y arraigo nos alarman de dia en día." ${ }^{12}$

Recordemos que en la pastoral de 1943, dedicada a la institución sacerdotal, Pérez Muñoz rindió un sincero homenaje a los clérigos inmolados, y al improbo esfuerzo del mermado grupo que, con abnegación, se afanaba por aquel entonces en las tareas apostólicas que la diócesis reclamaba ${ }^{13}$.

En el reiterado trabajo periodistico del 18 de julio de 1943 se aludía a la labor reconstructora de edificios de culto, acometida por el Nuevo Estado, mediante la Dirección General de Regiones Devastadas, y su auxiliar, la Junta Nacional de Templos Parroquiales. En el decreto fundacional de esta última, podía leerse:

«El sentido católico del Movimiento Nacional, si un imperativo de justicia no fuera suficiente acicate para ello, justifica la preocupación del Estado falangista por la reconstrucción de templos dañados a consecuencia de la revolución y de la guerra de liberación." ${ }^{14}$.

Cuatrocientos pueblos - se apuntaba- habían quedado sin iglesia en la zona republicana. La restauración de tales inmuebles ocupaba el segundo puesto entre todas las tareas del referido organismo: iban ya reparados cincuenta y cinco, y otros cien estaban en obras. El presupuesto invertido sobrepasaba los cincuenta millones de pesetas.

En la sección del Córdoba dedicada a la información provincial se recogian, con grandes caracteres, numerosas noticias atañentes a la re-

12 Ibid., 3 (1942), pág. 53. (Córdoba reprodujo parcialmente este fragmento, eludiendo la reconvención conclusiva, el dia 24 de tebrero de 1942, pág. 3 ).

15 ibid., 3 (1943), págs. 85-120. Nos consta que el actual canónigo archivero de la catedral cordobesa, don Manuel Nieto Cumplido, prepara un completo martirologio del clero secular diocesano. Junto a la célebre obra de A. MONTERo, vid. la monografia de CARCEL ORTI, V., La persecución religiosa en España durante la Segunda República (1931-1939). Madrid, 1990.

i. La orden constitutiva de la referida Junta apareció en el Boletín Oficial del Estado, del 27 de junio de 1941. 
construcción de parroquias y a la reposición de su ajuar litúrgico. Rara era la ocasión en que no se hacían constar sus promotores, el método de financiación y otras particularidades igualmente interesantes. Creemos que una relación, aunque no exhaustiva, sí puede ser provechosa ${ }^{15}$.

- El ejemplar correspondiente al 7 de agosto de 1941 daba cuenta de la finalización de las labores en la iglesia parroquial de la Asunción, en El Carpio, realizadas mediante una suscripción popular, iniciada por el duque de Alba, con cinco mil pesetas ${ }^{16}$. Se referia, asimismo, la adquisición de las imágenes de San José, la Purísima y el Corazón de Jesús, que sustituían a las destrozadas. Una mención especial se reservaba para el nuevo sagrario, erigido para perpetuar la memoria del sacerdote asesinado Luis León Muñoz.

- El 12 de agosto se anotaba el encargo de la junta directiva de la Cofradía de Nuestro Padre Jesús, de Fernán Núñez, al imaginero sevillano Manuel Cerguera Becerra, para que esculpiese una fiel reproducción de la venerada efigie, que el furor iconoclasta hizo desaparecer.

- El 27 del mismo mes se relataba la reunión celebrada bajo la presidencia del provincial de los Carmelitas Calzados, Rafael Rangel, que alcanzó el acuerdo de constituir una junta encargada de la administración de los fondos necesarios para reconstruir la parroquia de San Bartolomé, en Montoro ${ }^{17}$.

- El 28 de septiembre se informaba de la sesión convocada por fray Ladislao de Jesús, rector de la Asunción, Bujalance, encauzada a la recaudación de cantidades y conclusión de las obras del templo, que habia sido incendiado y destruido. Para tal fin se dictaminó el nombramiento de una comisión de feligreses. Al parecer, las capillas laterales habian sido ya erigidas mediante las aportaciones de varias familias piadosas, pero quedaba aún por recuperar el altar mayor. Se refería, además, la veneración popular al "Cristo de los tiros», apodo relacionado, como puede suponerse, con su azarosa suerte.

15. En el Archivo General del Obispado de Córdoba se conserva un completo informe sobre las destrucciones, profanaciones y saqueos, confeccionado, al término de la guerra, por el canónigo Félix Romero Menjibar, posterior ocupante de las sedes jiennense y vallisoletana. Un estudio basado en dicha documentación nos lo ofrece MORENO VALERO, M., "Expolio en el patrimonio artistico de la diócesis de Córdoba», Crónica de Córdoba y sus pueblos, Córdoba, 1991, II, pảgs. 142-148.

16 La casa ducal de Alba estaba asociada a la villa desde su entroncamiento con el marquesado de El Carpio, en el sigio xvII.

1) Con posterioridad -6 de noviembre de $1943-$, se nos referiria el levantamiento de la casa rectoral, por Región Devastada. 
- El 29 de marzo de 1942 se mencionaba la restauración de las iglesias de Santa Catalina y de San Sebastián, en Pozoblanco, que habian sido profanadas y convertidas en talleres mecánicos. Aunque las flamantes imágenes de sus titulares fueron costeadas por el Ayuntamiento, el adecentamiento de ambos edificios fue posible gracias a la contribución pecuniaria del propio vecindario. Días antes de la aparición en la prensa de tal nota, coincidiendo con el tercer aniversario de la entrada de las tropas franquistas en esta importante localidad de la comarca de Los Pedroches, se bendijo la talla de la Virgen de las Mercedes, donada, como las anteriores, por la corporación municipal pozoalbense.

- El 7 de noviembre de 1943 fue noticia, asimismo, la reconstrucción del templo parroquial de Espejo.

El número del 10 de octubre de 1941 divulgaba la aparición en el mundo publicístico de Almas y armas españolas, libro debido a la pluma del fogoso y pugnaz capuchino Jacinto de Chucena, quien pretendía documentar sobre la historia del Movimiento en Córdoba y su provincia. Para su reseñador, el trabajo, en el que descollaba su calidad analitica, constituía una valiosa aportación historiográfica. Podemos encuadrarlo, sin duda, en el mismo estilo apologético de Dolor y triunfo. Héroes y mártires en pueblos de Andalucia durante el Movimiento Nacional, obra impresa en 1944, de su hermano en religión, fray Antonio Aracil, OFM. Su tesis parece condensarse en el encabezamiento elegido para las reflexiones conclusivas: "Los Religiosos sacrificados por los marxistas fueron verdaderos mártires". 